\title{
COMPREHENSIVE COUNTRY ENERGY ASSESSMENTS USING THE MARKAL-MACRO MODEL
}

\author{
Ann W. Reisman \\ International Projects Division \\ Brookhaven National Laboratory \\ Upton, NY 11973 \\ Phone 516-344-2666 Fax 516-344-5344
}

RECEIVED

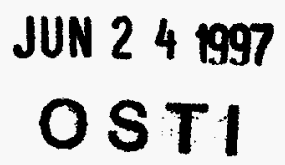

\begin{abstract}
A number of comprehensive country energy assessments were performed in the late 1970 s and early 1980 s in cooperation with the governments of various countries. The assessments provided a framework for analyzing the impacts of various national strategies for meeting energy requirements. These analyses considered the total energy framework. Economics, energy supply, national resources, energy use, environmental impacts, technologies, energy efficiencies, and sociopolitical impacts were some of the factors addressed. These analyses incorporated the best available data bases and computer models to facilitate the analyses. National policy makers identified the various strategies to examine. The results of the analyses were provided to the national policy makers to support their decision making.

Almost 20 years have passed since these assessments were performed. There have been major changes in energy supply and use, technologies, economics, available resources, and environmental concerns. The available tools for performing the assessments have improved drastically. The availability of improved computer modeling, i.e., MARKAL-MACRO, and improved data collection methods and data bases now permit such assessments to be performed in a more sophisticated manner to provide state of the art support to policy makers.

The MARKAL-MACRO model was developed by Brookhaven National Laboratory over the last 25 years to support strategic energy planning. It is widely used in the international community for integrating analyses of environmental options, such as reduction of greenhouse gas emissions. It was used to perform the analyses in the least cost energy strategy study for the Energy
\end{abstract}

Policy Act of 1992. Improvements continue to be made to MARKAL-MACRO and its capabilities extended.

A methodology to conduct Country Energy Assessments using MARKAL-MACRO is discussed.

\section{INTRODUCTION}

The United States undertook a major initiative in the late 1970 s to work cooperatively with other nations to support these Nations efforts to develop National Energy Plans. This initiative was conducted in response to a Presidential Directive. The Departments of State, Energy, Interior, and Treasury participated. A key part of these initiatives were Energy System Assessments.

The tools employed took advantage of the most advanced computers and computer modeling tools available at that time. Brookhaven National Laboratory's Reference Energy System (RES), a network representation of a nation's energy system, was the key analytic method used. The RES depicted energy technologies as elements of an integrated national energy system's supply and demand balance. The assessment examined the environmental and economic impacts of energy production, transportation, conversion, and end use.

The 1970 era assessments were performed cooperatively with experts from the participating country, interested U.S. Government agencies, Brookhaven National Laboratory (BNL), and experts in energy technology and systems analysis from BNL and other organizations. The assessments were extremely useful, but had limitations due to deficiencies in the energy data bases and data collection.

Over the intervening twenty year period, there have been major advances in computer technology and computer modeling. Energy

*This work performed under the auspices of the U.S. Department of Energy, Contract No. DE-AC02-76CH00016.

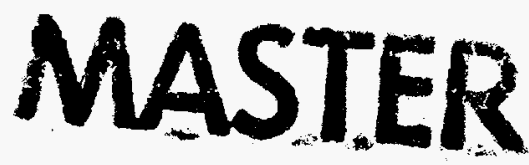


technologies, environmental technologies, national resources and the economics of energy and environmental factors have undergone profound changes. Databases have improved. Environmental issues and national resources are now recognized as being of key importance to the U.S. national interest (Goodman, 1996). It is recognized that the impacts of energy and the environment transcend national borders and directly threaten health, prosperity, and jobs. Addressing natural resource issues is frequently critical to achieving political and economic stability (Christopher, 1996).

Performance of integrated assessments provides policy makers information needed to make sound decisions. Current assessments are based on experience and use advanced computer modeling. BNL has developed and is using a linked energy/environmental/economic model MARKAL-MACRO that considers national and international energy, environmental, and natural resource issues, the focus of the environmental security concerns of senior policy makers and government leaders.

\section{COUNTRY ENERGY ASSESSMENTS}

The Cooperative Country Energy Assessments conducted in the late $1970 \mathrm{~s}$ responded to the needs of the time for a first order quantitative assessment of energy supply and demand, technologies and environmental impacts. Now twenty years later we have important new needs for integrated energy, environmental and economic assessments and demonstrated new methods to respond to these needs. National concerns with the impacts of energy use on the environment and the economy require sound analyses of the current situation, along with potential strategies, options, and the effects potential decisions may have. These concerns are often international, with key decisions made by leaders in the various countries of the world.

Current country energy assessments are once again needed to provide a basis for national and international decision making. Due to the increased breadth and complexity of the concerns these assessments address, they must be conducted in many nations and regions in a consistent framework. Focusing attention on a few priority nations, which was sufficient to satisfy the policy needs twenty years ago, will not satisfy the need to achieve global environmental security today.

The Global Climate Change Initiative in support of the 1992 U.N. Framework Convention on Climate Change (FCCC), addresses the need to curb greenhouse gas emissions and has over 150 nations as signatories. This initiative demonstrates that global action, consistent planning, and international cooperation to solve environmental issues is a serious and a practical undertaking. The ability of nations and regions to work together to solve these important and difficult issues can be greatly enhanced by performance of consistent assessments, thus allowing national leaders to prioritize activities, integrate planning with others to implement least cost strategies, and to collectively define and implement effective energy, environmental, and natural resource initiatives at a supranational level.

The MARKAL-MACRO model can serve as the basis of an updated country assessment methodology. How the implementation of the methodology in each country is accomplished will vary in response to national requirements and desire for collaborative assistance.

\section{MARKAL-MACRO OVERVIEW}

The key analytic tool for the proposed country energy assessments is MARKAL-MACRO. It can be used with ad hoc, complementary electric system capacity expansion, district heating, and other models of specific technologies or issues.

MARKAL-MACRO is a "bottom up engineering"/ "top down macroeconomic" model to support planning and policy making. It provides an enhanced model of nations or regions that integrates energy, environmental and economic factors. The model assists leaders and policy makers to understand the implications of alternative various energy or environmental strategies and policies. It is the only widely available (over 35 countries have MARKAL models), internationally accepted method to identify, in a transparent way, the impact of national and international energy, environmental, and natural resource issues using a technology-specific database. This level of detail allows reasoned responses to environmental security concerns of senior leaders.

MARKAL-MACRO provides least cost solutions, together with economic measures of cost and benefits. It ranks the relative merits of various technologies for various specific applications in the entire energy system. Standard outputs include optimal mixes of fuels and technologies, definition of the emission sources and levels (e.g., $\mathrm{CO}_{2}, \mathrm{SO}_{\mathrm{X}}, \mathrm{NO}_{\mathrm{X}}$ ) for various strategies, marginal cost for various technologies and applications, and specifics such as the value of carbon rights (marginal cost of emissions).

MARKAL-MACRO is the only such technology-rich model selected by the U.S. to support the U.N. Framework Convention on Climate Change (FCCC) 1992. An objective of this application of MARKAL-MACRO is to identify concrete steps to curb emissions of greenhouse gases.

MARKAL-MACRO is also used in other applications, such as examination of:

- $\quad$ the impact on a specific energy system (existing or proposed) of substitution of new or more efficient energy technologies;

- the impact of proposed environmental regulations on specific existing, or hypothetical (proposed) energy systems costs and environmental emissions; the least cost energy system to meet projections of energy demand;

- $\quad$ assessments of energy systems in nations, regions, states, and multi-nation or state regions;

local energy planning for cities or small regions.

Selected analyses performed using these methods are:

- $\quad$ the Least Cost Energy Strategy Study mandated by the Energy Policy Act of 1992, completed in 1995; international comparison studies to examine marginal cost of carbon reduction completed in 1995 and provided to the Intergovernmental Panel on Climate Change; 
an assessment of the full cost of $\mathrm{SO}_{\mathrm{X}}, \mathrm{NO}_{\mathrm{x}}$, and $\mathrm{PM}_{10}$ emissions from electric generation completed in 1996 for the US Department of Energy.

\section{MARKAL-MACRO DETAILS}

MARKAL-MACRO links two models, MARKAL (MARKet ALlocation) and MACRO (Hamilton et al., 1992) to analyze specific energy, environmental, and natural resource strategies, options, and/or policies over time. The driver is energy service demand in the base year, such as the number of square feet in a building to be heated. The model user can specify the degree of aggregation in demand.

MARKAL is a linear programming model, structured according to a network showing possible routes for each source of primary energy through each of the steps leading to each end use demand sector. This network includes emissions and environmental impacts for the activities in each step from the basic natural resource to the end use, e.g., extraction/mining, transportation of all forms, conversion, etc. MARKAL describes the routes, energy conversion and distribution technologies, the end use technologies, and various environmental protection options. Technical, environmental, and economic properties of the various technologies, including any technical, behavioral, or policy constraints on implementation are described in MARKAL. Examples of parameters are energy efficiency, emissions, environmental effects, energy costs, capital investment, and availability.

MACRO is a non-linear macroeconomic model that provides an aggregate representation of long-term economic growth and the role of energy, and other factors in energy production and consumption. The model acts to allow capital and labor to be substituted directly for each other. This allows price-induced conservation to operate by lowering the marginal productivity of capital and labor. The model provides transparency and avoids double counting.

MARKAL-MACRO combines the capabilities of these two models into a single model. It can optimize the aggregate investment in the energy sector and the growth or decline in GNP using a variety of economic assumptions that can be specified. It can identify least-cost energy systems configurations, strategies, and policies to meet predetermined demands for energy services with appropriate feedback from the economy.

MARKAL-MACRO was designed specifically to support decision making related to reducing environmental risks. Assessments of environmental risk must address long-range changes in energy systems, the environment, and natural resources. For this reason MARKAL-MACRO was designed and developed to be able to capture the complex network of relations within the energy systems over time while allowing for options for changes and the impact of these changes on the economy and the environment. This development took advantage of the characteristics of both MARKAL and MACRO.

MARKAL uses dynamic linear programming. The end demands are fixed, and economically efficient solutions are obtained that minimize the value of system cost during the period of the analyses. MACRO uses nonlinear optimization, with optimization on the basis of maximum discounted utility of consumption. The results select from alternative time paths of energy cost, macroeconomic, consumption, and investment. Both use "look-ahead" features to make choices and are based on the concept of a single representative supplier/user. Energy demands are exogenous parameters in MARKAL, but are developed endogenously in MARKAL-MACRO. The coupling of MARKAL and MACRO allows energy demands to become internal parameters determined by macroeconomic growth and conservation. Energy costs impact capital accumulation and economic growth. Substitution and conservation based on technologies as well as environmental impacts take place within the MARKAL portion of the model. Natural resource use is dealt with in both the MARKAL and MACRO portions of the model. Energy system costs drive the MARKAL portion, while economic impact drives the MACRO portion.

There are flows of energy from MARKAL into MACRO, and there are energy cost payments from MACRO into MARKAL. The linkage is based on an economy-wide production function. This enables a direct link between analyses of physical processes and long-term macroeconomic growth.

\section{MARKAL - MACRO FORMULATION}

To run MARKAL-MACRO, a reference case is developed. A series of sensitivity analyses are then performed which can be used to examine the impact of varying use of a individual natural resource, a technology, a policy, environmental constraints, etc. Scenarios are developed to examine mixes of these components. Some standard outputs from a model run include total system cost, marginal costs for each technology, emissions, energy flows, energy consumed and GDP.

\section{COUNTRY ENERGY ASSESSMENTS AND MARKAL- MACRO}

When MARKAL-MACRO is used as the primary tool in a country energy assessment, experience has shown that success depends on heavy involvement of the participating country analysts in data collection, scenario development and analysis of model results. This involvement requires development of a close working relationship between the MARKAL-MACRO experts and the country analysts assigned to the assessment.

To start, training and education in methods and activities required to perform the assessments is required and may include: - $\quad$ the analytic methods, i.e., MARKAL-MACRO and any auxiliary models;

- data collection and organization;

- use of consistent, integrated data bases;

- $\quad$ making country, or region, specific modifications to existing data bases to satisfy local needs;

- $\quad$ planning and specification of analyses;

- $\quad$ reviewing data, modeling, and analytic assumptions;

- $\quad$ specifying strategies (scenarios) to be analyzed. 
Initial MARKAL-MACRO education and training is normally provided in workshops for key people, such as a three week workshop on MARKAL-MACRO to be conducted in September 1997 at Brookhaven National Laboratory. Workshops of shorter duration may be conducted for senior officials and policy makers, reserving the more detailed workshops for people who will be conducting the assessments. These workshops are often given to people from various countries at the same time.

In cases where a nation will be independently conducting an assessment, the workshop can be supplemented with support and consulting services during the course of the assessment. Technology transfer and education can also occur by collaboration on a day to day basis in performing cooperative energy assessments.

In setting up a cooperative assessment between a country and the U.S., a crucial initial step is selecting the people who will be performing the assessment and making arrangements with the organizations in the participating country(s) to provide needed support and data. The participants (from the country or region being assessed and the US) must perform the detailed planning, scheduling, and organization of the work. Supplemental training may be required in organizations providing, or collecting data, who are not direct participants in modeling or analysis of the data. It is essential that all participants understand what is being done and why. They must be in a position to assure that data and information they provide is used properly with the uncertainties and limitations recognized.

The definition of the initial strategies and options to be evaluated in the assessment is normally decided before the assessment is undertaken. However, it may be when an clear assessment is underway that some strategies are found to be trivial (as they are almost the same as other strategies) or impractical to implement (due to economic, institutional, or cultural factors). It is therefore necessary that close working contact be maintained with the authority responsible for the assessment and those conducting the assessment to obtain timely redirection or fine tuning of work.

Presentation and documentation of assessment results are the project deliverables. Close collaboration with all participants is required to obtain all of the required documentation. While the backup and detailed documentation must be prepared and organized, such data are so voluminous and specialized that they of little direct use to the leaders and policy makers who must receive and use the results of the assessment. The final deliverable is a document with an Executive Summary clearly stating the findings. This deliverable should not make recommendations, but should identify options and implications of selection of these options. The findings should describe in transparent terms the basis for the findings.

An independent review by the authority responsible should be conducted to assure the findings are understandable, that the findings are supported, and that the statements and presentation are acceptable. The assessment, regardless of its quality and potential impact, will be of little use if the presentation is not understandable, is perceived as ambiguous, or raises political or socio-economic issues.

The geographic focus of the assessment is usually national, but other areas may be used such as cities or regions within the nation. For example, performance of assessments in individual countries in a region may be practical and could use a consistent approach. However, due to the economic linkages a regional multi-country assessment might be more beneficial. Another situation is represented by very large countries such as Russia and China. These nations are so large and diverse that an assessment may be best performed on a regional basis and then aggregated to perform a national assessment.

\section{NEXT STEPS}

A start toward cooperative country assessments has already been made with the present work to support the Global Climate Change Initiative and with the presentation of the ongoing series of MARKAL-MACRO Workshops. Expanded use of country energy assessments to provide information and analyses to national leaders and policy makers can enhance their understanding potential of the impacts of various decisions involving energy, the environment, and natural resources.

Planning for future assessment efforts could profit by a top level, global survey of the existing data bases and analytic efforts that are currently influencing planning and policy related to energy, the environment, and natural resources. Efforts to increase international data sharing and comparisons of technology planning should be encouraged. Additional activities to encourage cooperative efforts such as performing comparable analyses leading to joint implementation of emission reduction projects and participating in multi-country regional analyses, should continue to be given high priority.

The importance of expanding ongoing country assessments is emphasized in the introduction to the Memorandum of Understanding (MOU) among the EPA, DOE, and DOD concerning Cooperation in Environmental Security signed in July, 1996. This states, in part:

\footnotetext{
"America's national interests are inextricably linked with the quality of the earth's environment, and threats to environment's quality affect broad economic and security interests, as well as the health and well-being of individual citizens";

"Environmental security, including considerations of energy production, supply, and use, is an integral component of United States national security policy and strong environmental security contributes to sustainable development."
}

Country Energy Assessments can provide important insights to the undertakings envisioned by the MOU and have global as well as national benefits. 


\section{REFERENCES}

Christopher, W. M., 1996, “American Diplomacy and the Global Environmental Challenge of the 21st Century", Stanford University

Goodman, S. W., 1996, "International Environmental \& Security Issues in Professional/Military Education", National Defense University

Hamilton, L. D., Goldstein, G. A., Lee, J., Manne, A. S., Marcuse, W., Morris, Samuel, C., Wene, C., 1992," MARKAL-MACRO: An Overview", BNL-48377, Upton, NY

\section{DISCLAIMER}

This report was prepared as an account of work sponsored by an agency of the United States Government. Neither the United States Government nor any agency thereof, nor any of their employees, makes any warranty, express or implied, or assumes any legal liability or responsibility for the accuracy, completeness, or usefulness of any information, apparatus, product, or process disclosed, or represents that its use would not infringe privately owned rights. Reference herein to any specific commercial product, process, or service by trade name, trademark, manufacturer, or otherwise does not necessarily constitute or imply its endorsement, recommendation, or favoring by the United States Government or any agency thereof. The views and opinions of authors expressed herein do not necessarily state or reflect those of the United States Government or any agency thereof. 


\section{DISCLAMMER}

Portions of this document may be illegible in electronic image products. Images are produced from the best available original document. 